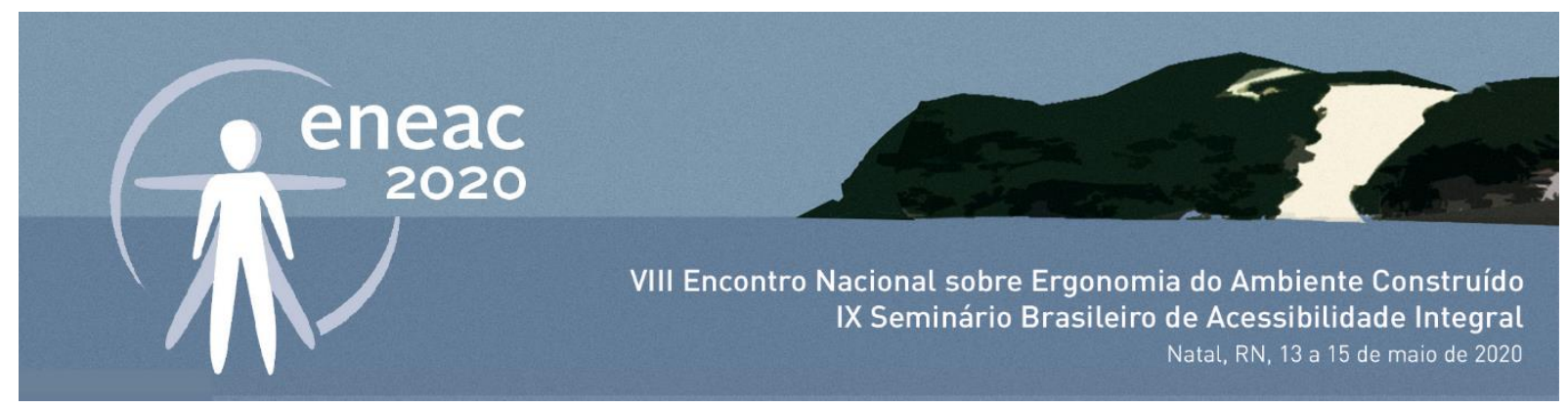

\title{
Arquitetura inclusiva: Análise dos ambientes destinados às crianças autistas em uma Instituição de Blumenau/SC
}

\author{
Inclusive architecture: Analysis of the environments involved in \\ autistic children in an institution in Blumenau / SC
}

\author{
VERONICA ANDRZJEVSKI \\ Acadêmica de Arquitetura e Urbanismo, UNIDAVI, veronica.andrzjevski@unidavi.edu.br \\ PATRÍCIA GEITTENES TONDELO
}

Mestre em Arquitetura e Urbanismo, UNIDAVI, ptondelo@unidavi.edu.br

MARINA BERNARDES

Mestre em Arquitetura e Urbanismo, UNIDAVI, marina.bernardes@unidavi.edu.br

\section{RESUMO}

O Transtorno do Espectro Autista (TEA) abrange uma série de condições que acarretam a habilidade de falar e interagir socialmente com outras pessoas. Grande parte das crianças com autismo enfrentam diversas dificuldades de adaptação ao meio social, devido à falta de estímulo e tratamento adequado para essas habilidades. O espaço construído pode contribuir para o desenvolvimento dessas habilidades por meio de equipamentos tais como, salas de estimulação sensorial, espaços voltados para terapias e fonoaudiologia, entre outros, os quais podem estimular características psicomotoras e sociais. Diante disso, este estudo teve como objetivo, analisar a partir de uma avaliação pós-ocupação, o espaço físico e funcional de uma instituição de apoio a criança autista na cidade de Blumenau. Deste modo, a finalidade foi o compreender aspectos funcionais, físicos e ergonômicos do espaço, e assim, gerar reflexões sobre como a arquitetura pode ser inclusiva, e ajudar no desenvolvimento de crianças com TEA. Os resultados demonstraram que em função do baixo orçamento, a Instituição tem dificuldades para atender a demanda de Blumenau e região, uma vez que o espaço físico possui quantidade de profissionais insuficiente para a realização dos atendimentos, considerando a demanda existente.

PALAVRAS-CHAVE: Autismo; Arquitetura inclusiva, Avaliação Pós-Ocupação.

\section{ABSTRACT}

Autistic Spectrum Disorder (ASD) covers a number of conditions that entail the ability to speak and interact socially with other people. Most children with autism face several difficulties in adapting to the social environment, due to the lack of stimulation and adequate treatment for these skills. The built space can contribute to the development of these skills through equipment such as sensory stimulation rooms, spaces for therapies and speech therapy, among others, which can stimulate psychomotor and social characteristics. Therefore, this study aimed to analyze, from a post-occupation assessment, the 


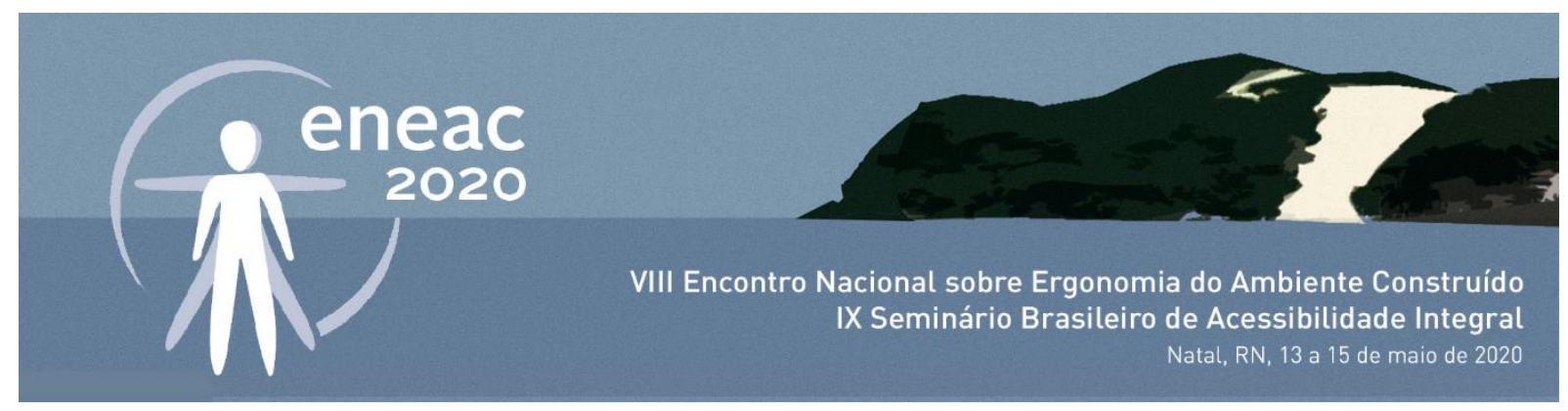

physical and functional space of an institution supporting autistic children in the city of Blumenau. Thus, the purpose was to understand functional aspects of the space, and thus, generate reflections on how architecture can be inclusive, and help in the development of children with ASD. The results showed that due to the low budget, the Institution has difficulties to meet the demand of Blumenau and region, since the physical space has insufficient number of professionals to perform the services, considering the existing demand.

KEYWORDS: Autism; Inclusive architecture, Post-Occupancy Assessment.

\section{INTRODUÇÃO}

O Transtorno do Espectro Autista (TEA) consiste em uma série de condições caracterizadas por algum grau de comprometimento no comportamento social, na comunicação e na linguagem (OPAS/OMS, 2017). O transtorno geralmente acarreta dificuldades de adaptação aos ambientes escolares convencionais, bem como requer o acompanhamento de diversos profissionais para estimular o desenvolvimento da criança, tais como psicólogos, terapeutas, fonoaudiólogos, entre outros.

Entende-se que o espaço construído transmite sensações e percepções distintas para o usuário que o utiliza. Para crianças dentro do Espectro Autista, principalmente as que possuem hipersensibilidade, essas percepções ficam ainda mais evidentes influenciando no desenvolvimento de suas habilidades psicomotoras.

Este estudo tem como finalidade estudar o espaço e o funcionamento de uma instituição de apoio a criança autista município de Blumenau/SC com o intuito de compreender a atual realidade do espaço destinado ao tratamento destas crianças, bem como gerar reflexões sobre como a arquitetura pode ser inclusiva e ajudar no desenvolvimento de crianças com TEA.

\section{TRANSTORNO DO ESPECTRO AUTISTA (TEA)}

O Transtorno do Espectro Autista (TEA) é uma condição que influencia na comunicação e no comportamento social, na comunicação e na linguagem (CDC - Center for Disease Control and Prevention, 2018). Sendo assim, pessoas com TEA tendem a se comunicar, interagir, se comportar e aprender de maneiras diferentes da maioria das outras pessoas.

O interesse inicial sobre o autismo surgiu da classe médica no início do século XX com o psiquiatra Eugene Bleuler (SCHMIDT, 2013). Apesar deste pesquisador ter citado pela primeira vez o termo autismo em 1916, somente 29 anos depois, o que atualmente se define por autismo foi apresentado em publicações do psiquiatra Leo Kanner e do pediatra Hans Asperger (SCHMIDT, 2013). A partir disso, diversas pesquisas e avanços em relação ao conhecimento sobre o TEA surgiram.

De acordo com estimativas da Rede de Monitoramento de Incapacidades do Autismo e Desenvolvimento de Deficiências (ADDM) do CDC (2014), 1 em 59 crianças foram identificadas com TEA. Estima-se que no mundo existam cerca de 75 milhões de pessoas com Transtorno do Espectro Autista (SOARES, 2017).

Os indivíduos neurotípicos, aqueles que não são acometidos por psicopatologias, recebem informações de todos os seus sentidos de uma vez só: audição, tato, olfato, paladar, vestibular e propriocepção (WHITMAN, 2015). Segundo o mesmo autor, esse processo denominado integração 


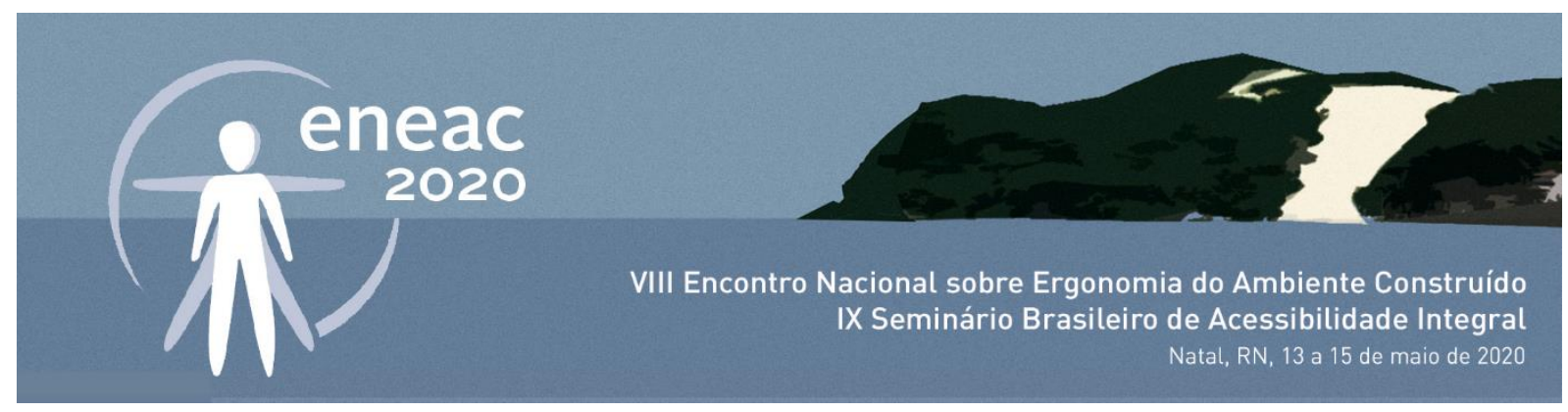

sensorial é justamente a habilidade que falta a maioria dos indivíduos com autismo (Figura 1). Tal processo influencia diretamente na forma que o indivíduo participa e se envolve em atividades ocupacionais a sua volta, afetando a organização de seu comportamento. "Por afetar diretamente o envolvimento ocupacional do indivíduo, o terapeuta ocupacional é o profissional que utiliza a abordagem de Integração Sensorial para avaliar e intervir sobre as dificuldades de processamento sensorial" (MENDES, COSTA, 2018).

Figura 1 Integração sensorial

INTEGRAÇÃO SENSORIAL

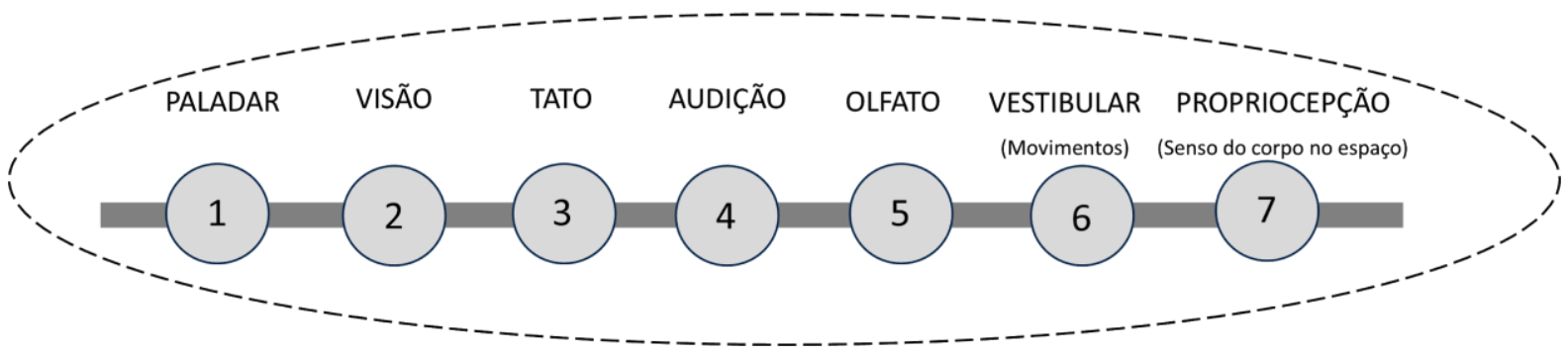

Fonte: Adaptado pelas autoras de WHITMAN, 2015.

Existem duas categorias distintas de sensibilidade sensorial entre os autistas, a HIPER-sensibilidade e A HIPO-sensbilidade (SOARES, 2017). Os indivíduos hipersensíveis mostram sensibilidade extrema às informações que seus estímulos recebem, fazendo com que fujam das experiências sensoriais. Já os hiposensíveis têm dificuldades para identificar os estímulos que recebem, buscando assim mais estímulos para obterem-se sensações (SOARES, 2017).

$\mathrm{Na}$ atualidade existe uma variedade de tratamentos que envolvem o ambiente construído como forma de desenvolvimento destes sentidos afetados pelo distúrbio. Dessa forma, observa-se que a arquitetura tem capacidade de influenciar nas experiências sensoriais e consequentemente auxiliar no desenvolvimento destas habilidades sensitivas e psicomotoras dos indivíduos com TEA.

\footnotetext{
O ambiente "fala", transmite-nos sensações, evoca recordações, passa-nos segurança ou inquietação, mas nunca nos deixa indiferentes. $O$ espaço [...] possibilita oportunidades para a aprendizagem, por meio das interações possíveis entre crianças e objetos e delas entre si. A partir desta perspectiva, o espaço nunca é neutro, podendo ser estimulante ou limitador de aprendizagens, dependendo das estruturas espaciais que estão postas e das linguagens que estão representadas. (VERGARA, TRONCOSO, RODRIGUES. apud. REDIN, MULLER, REDIN, 2007, p. 102).
}

Segundo Laureano (2017), os aspectos construtivos de concepção, uso e operação de um espaço estão ligados à sua forma, cor, luz, materiais utilizados, configuração de planta, etc. Estes aspectos também conectam-se aos conceitos de conforto, funcionalidade e bem-estar dos usuários, provocando sensações e afetando o comportamento e desses indivíduos.

Junto ao ambiente construído, uma equipe multidisciplinar deve conduzir o tratamento dos indivíduos com TEA (Figura 2). As ações de tais equipes consistem na orientação familiar, desenvolvimento da linguagem e/ou comunicação e incentivo a uma boa qualidade de vida das crianças autistas. Dentre os diversos profissionais que auxiliam no ensino e desenvolvimento de crianças com TEA destacam-se: neuropediatras, psicólogos, fonoaudiólogos, psicopedagogos, pedagogos, fisioterapeutas, musicoterapeutas, terapeutas ocupacionais e nutricionistas (SOARES, 2017). 


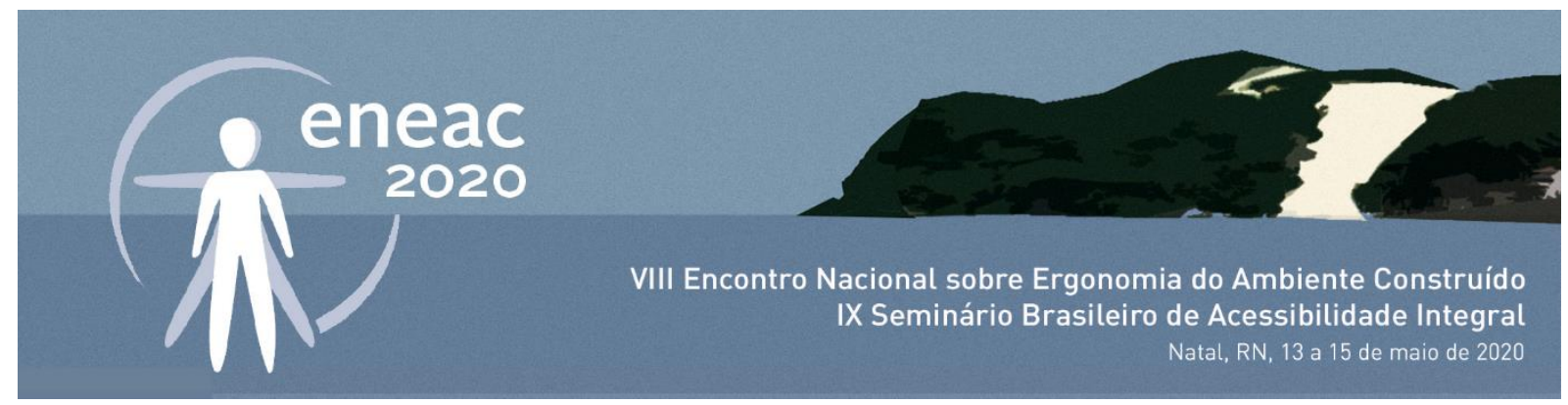

Figura 2: Equipe multidisciplinar

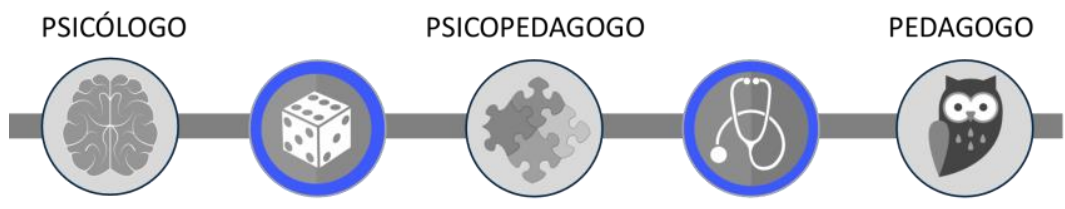

TERAPEUTA OCUPACIONAL

NEUROLOGISTA
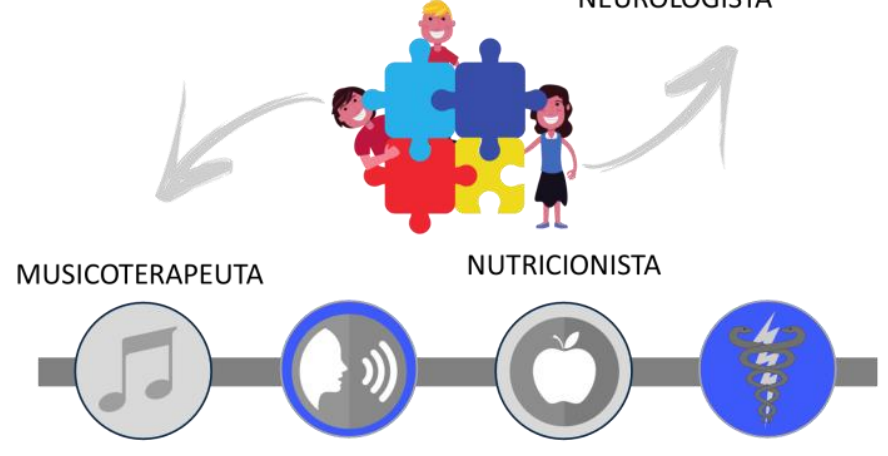

FONOAUDIÓLOGO

FISIOTERAPEUTA

Fonte: Adaptado pelas autoras de Soares, 2017.

O atendimento para cada criança é específico, pois dependendo do grau do transtorno e de suas singularidades, normalmente um tratamento depende do outro, trabalhando em equipe. Por se tratar de um espectro, não existe uma criança com autismo igual outra, deve sempre tratar-se de forma individual (WHITMAN, 2015).

\section{MÉTODO}

Esta pesquisa pode ser classificada como qualitativa, pois objetiva buscar a valorização do contato direto por meio de estudos de caso. Segundo Yin (2001), o estudo de caso "investiga um fenômeno contemporâneo dentro de seu contexto da vida real, especialmente quando os limites entre o fenômeno e o contexto não estão claramente definidos". Desta forma o estudo da instituição objetiva investigar e caracterizar a atual situação do local destinado a atender crianças com TEA por meio de uma Avalição Pós Ocupação (APO).

“A APO diz respeito a uma série de métodos e técnicas que diagnosticam fatores positivos e negativos do ambiente no decorrer do uso, a partir da análise de fatores socioeconômicos, de infra-estrutura e superestrutura urbanas dos sistemas construtivos, conforto ambiental, conservação de energia, fatores estéticos, funcionais e comportamentais, levando em consideração o ponto de vista dos próprios avaliadores, projetistas e clientes, e também dos usuários." (ROMERO E ORNSTEIN, 2003, p. 26)

Ornstein (2013) ainda afirma que a APO é um método que conta com as particularidades de cada ambiente, o que pode levar a alterações constantes nas técnicas aplicadas, sendo, portanto, específica para cada estudo de caso dependendo do ambiente e realidade. Dessa forma, APO abordou análises referentes à estrutura funcional e física do local. Por meio de uma visita in loco foram levantadas informações acerca de aspectos arquitetônicos, com auxílio de levantamento 


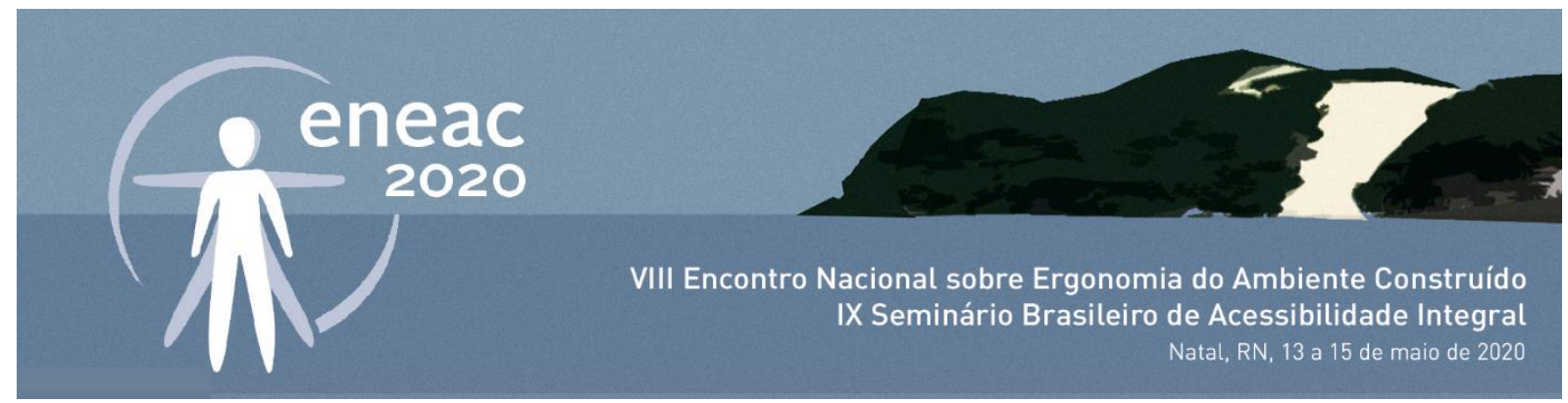

fotográfico e conversas com os profissionais, sendo estruturada de acordo com o planejamento apresentado na Figura 3.

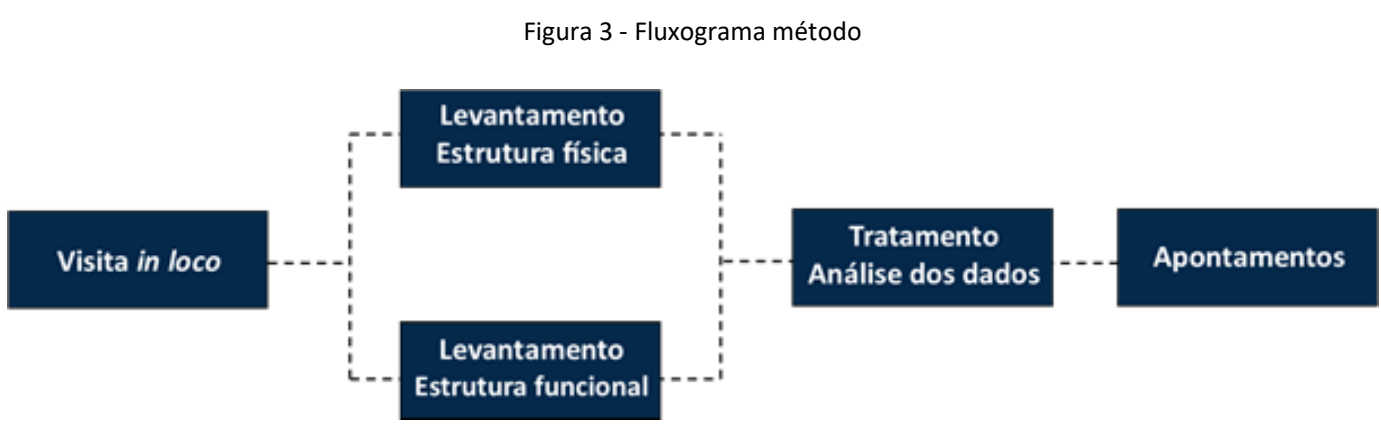

Fonte: Das autoras, 2019.

Quanto à estrutura funcional, coletaram-se dados relativos ao número de profissionais e tipos de terapias oferecidas no local. Sobre ao espaço físico, analisou-se arquitetonicamente a edificação utilizada para fins de atendimento às crianças, avaliando questões relativas ao conforto ambiental e a ergonomia. O conforto ambiental abordou análise da configuração de planta, à insolação, à ventilação, as cores, ruídos externos. De outro modo a ergonomia abordou análises com relação ao atendimento a norma NBR 9050, relação dos usuários com o ambiente relacionado as suas dimensões e forma, relação do usuário com os mobiliários. Somado isso, também foi realizada uma verificação com relação à disponibilidade de brinquedos e equipamentos específicos para o atendimento das crianças, assim como questões relativas ao acesso via transporte público e privado. Os dados coletados foram tratados e organizados em textos, esquemas e quadros de forma a sintetizar os aspectos abordados, bem como apresentar apontamentos relativos à atual estrutura oferecida para tratamento de crianças com TEA na cidade de Blumenau/SC e indicando se a instituição tem um espaço adequado ou não.

\section{RESULTADOS E DISCUSSÕES}

A instituição localiza-se no centro da cidade de Blumenau, na região do Médio Vale do Itajaí, Santa Catarina e atende atualmente crianças de 0 a 14 anos com TEA de Blumenau/SC. A Instituição surgiu em 2013, porém desde o ano de 2010 o grupo já realizava encontros com pais e responsáveis de crianças com TEA da cidade de Blumenau e região. Os encontros eram pontuais, duas a três vezes por ano, e tinham o intuito de discutir assuntos e dúvidas das famílias das crianças com autismo. A Associação surgiu da necessidade dos pais das crianças em lutar pelos direitos de seus filhos que apresentavam dificuldades para matrícula e manter as crianças em escolas regulares.

$\mathrm{Na}$ época foram realizadas algumas pesquisas e visitas, a fim de identificar alguns pontos importantes para a formalização da associação, até que em 15 de agosto de 2013, reuniram-se em assembleia, na sede da Fundação Fritz Müller, para criar a instituição na cidade de Blumenau.

O estudo de caso foi realizado no dia 12 de setembro de 2019. O espaço destinado a instituição localiza-se no segundo pavimento de um edifício comercial no centro de Blumenau e possui área 


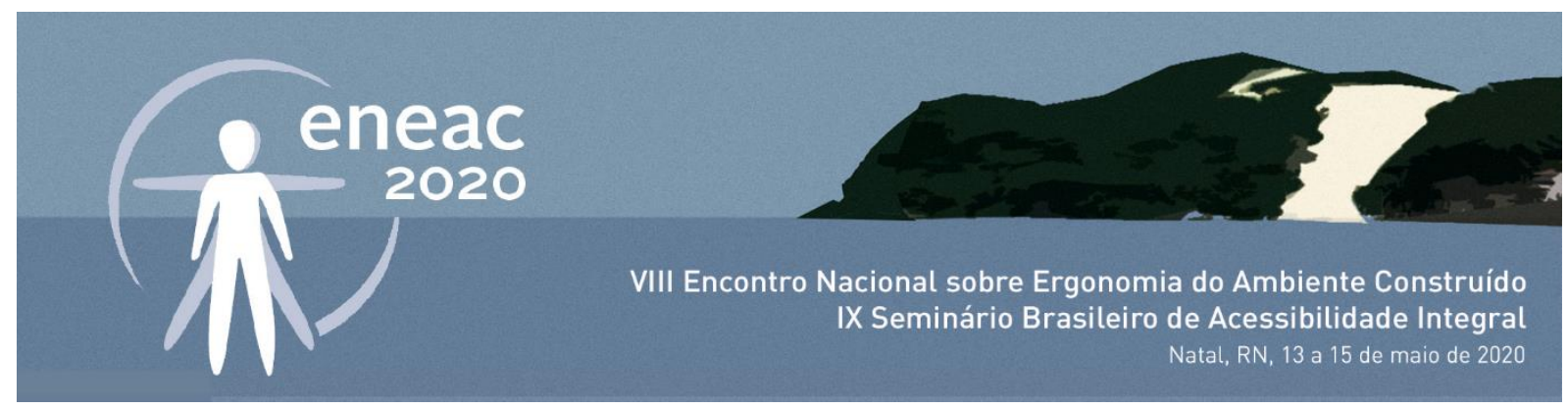

total de 59,69 $\mathrm{m}^{2}$. O espaço é de um particular que cede para uso sem cobrança de aluguel. O imóvel em questão não pertence a instituição, utiliza-se o local de forma gratuita e paga apenas despesas de água, luz e condomínio. A instituição arrecada fundos por meio de doações, ajudas voluntárias e eventos destinados a arrecadação de fundos. O mobiliário foi adquirido por meio de doação de um antigo membro da instituição.

Em relação ao entorno, observou-se a existência de semáforos e faixas de pedestres próximos e ponto de ônibus que facilitam o trânsito de pessoas que chegam ao endereço caminhando. As calçadas estão em bom estado e encontram-se acessíveis (Figuras 4 e 5). 0 ponto de ônibus se distancia em média a 500 metros do acesso do edifício. Dessa forma, considera-se que o acesso ao edifício é feito de maneira segura pelos usuários. Durante as visitas também foi observado que edifício não possui estacionamento próprio, deste modo os usuários que utilizam veículo próprio podem estacionar em nas vias do entorno em vagas rotativas e pagas, ou ainda em estacionamento privativos pagos.

Figura 4: Vista do edifício

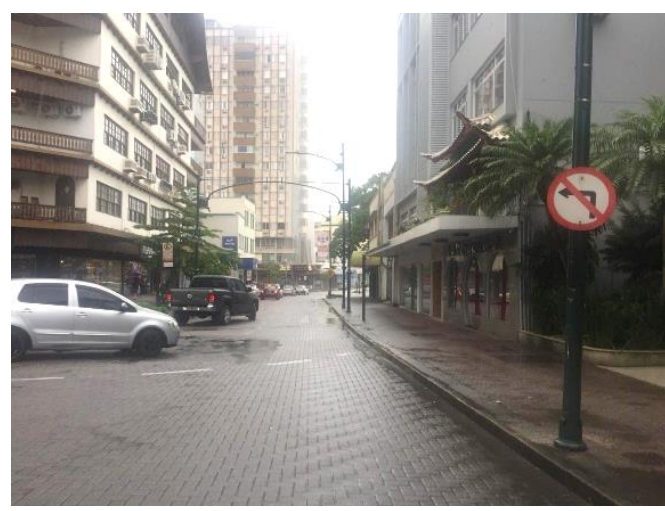

Fonte: Das autoras, 2020
Figura 5: Entorno do edifício

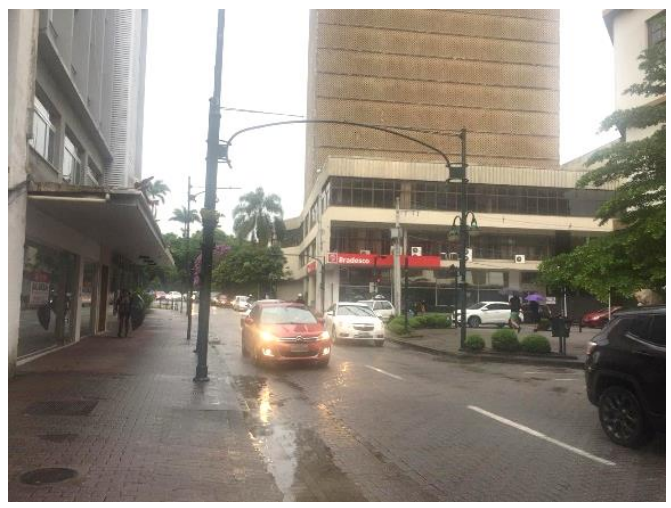

Fonte: Das autoras, 2020.

A partir de 2012, a Lei № 12.764 (Lei Berenice Piana) instituiu-se a Política Nacional de Proteção dos Direitos da Pessoa com Transtorno do Espectro Autista, que estabelece que a pessoa com transtorno do espectro autista é considerada pessoa com deficiência para todos os efeitos legais (BRASIL, 2012). No entorno imediato da edificação foi identificada apenas uma vaga para PCD - Pessoa com Deficiência, visto que pessoas com autismo possuem o direito de utilizá-las.

Segundo Lucio (2007), através da integração entre acessibilidade, antropometria, design ergonômico, design universal, ergonomia e usabilidade, torna-se possível empregar soluções mais condizentes com as reais necessidades dos usuários, permitindo contemplar diversas potencialidades, que não seriam adequadamente atendidas através da ótica de uma única área do conhecimento. Como apontado por Montmollin (2007), a ergonomia não é só análise da atividade, bem como a análise da atividade pode ser utilizada em outros domínios que não o do trabalho, dessa forma as análises podem ser aplicadas também na instituição.

A ergonomia não ocupa-se só da relação do homem com o objeto, mas também do homem com o ambiente onde está inserido. Nesse sentido evidencia-se a necessidade dos conhecimentos da Ergonomia nos projetos em Arquitetura e Design de Interiores visto que o ambiente arquitetônico é 


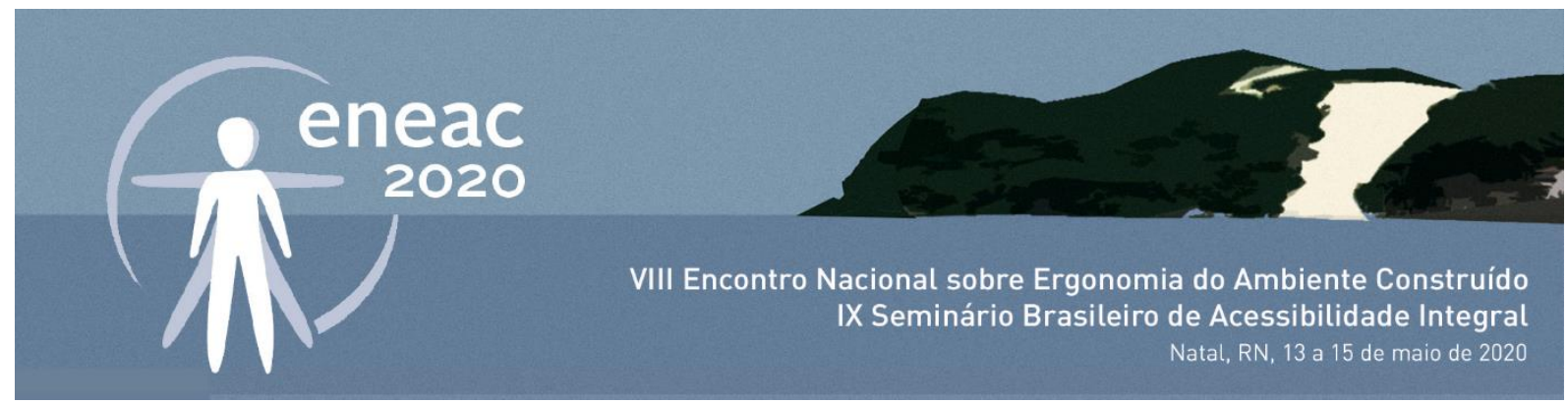

o local onde o usuário desenvolve suas tarefas. (MORAES, 2004, p.68 apud OLIVEIRA, MONT'ALVÃO, 2015).

No que tange ao edifício, observou-se que o mesmo possui escada e elevador para fazer acesso às salas em bom estado de conservação, porém, os espaços de circulação encontram-se atualmente em reformas. A Figura 6 mostra a planta baixa da sala produzida a partir do levantamento arquitetônico. As nomenclaturas e números estão associados às fotografias posteriormente exibidas.

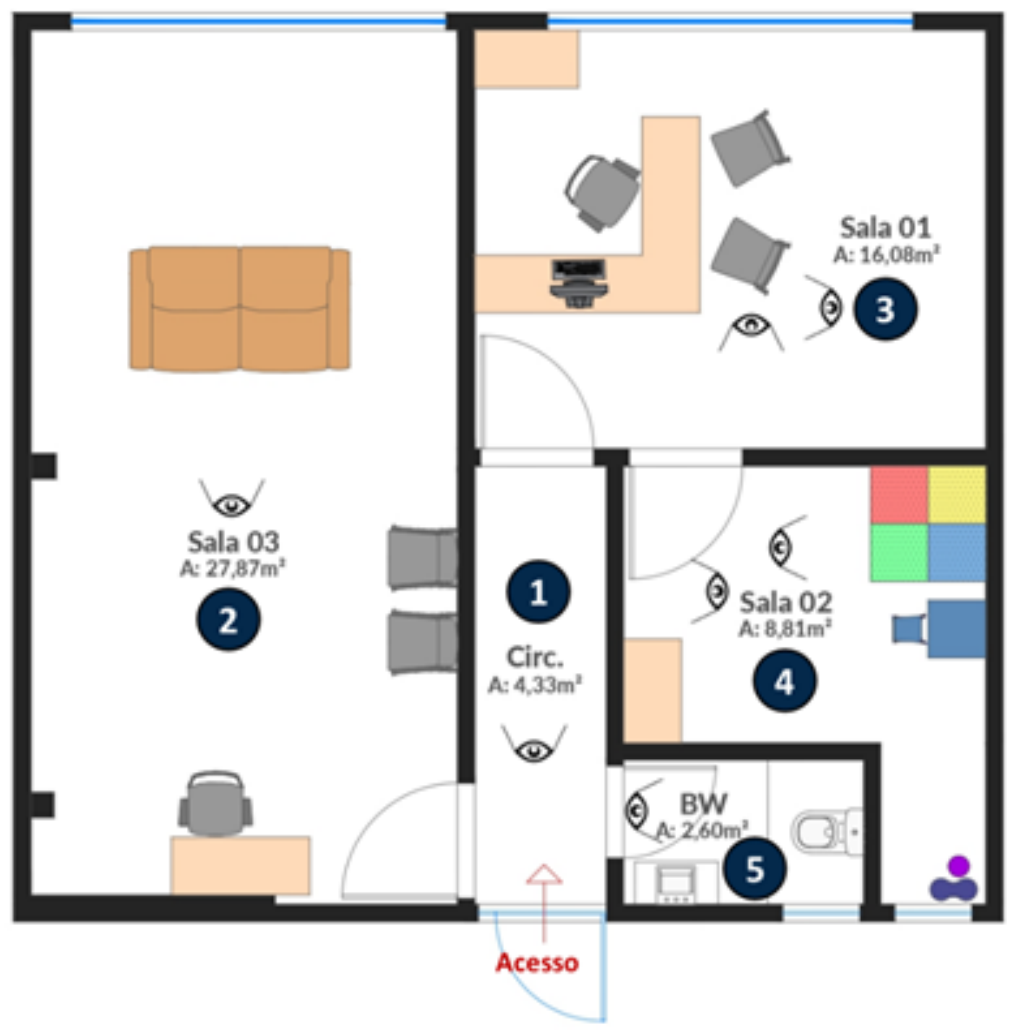

Fonte: Elaborado pelas autoras, 2019.

O acesso para o espaço ocorre por uma porta de vidro que separa o espaço destinado a Instituição das demais salas e consultórios neste mesmo pavimento do edifício. Pelo corredor é possível acessar a Sala 01 e Sala 03 e o sanitário, porém, para acessar a Sala 02 é necessário acessar a Sala 01 primeiramente.

A Sala 01 possui 16,08 $\mathrm{m}^{2}$ e é utilizada como recepção, administração e atendimento dos pais ou responsáveis. A sala contém um armário vertical, bem como, um computador, uma impressora, uma mesa e três cadeiras para atendimento do público. A iluminação e insolação pode ser considerada adequada em função da ampla abertura na fachada norte, porém, durante a visita foi possível 


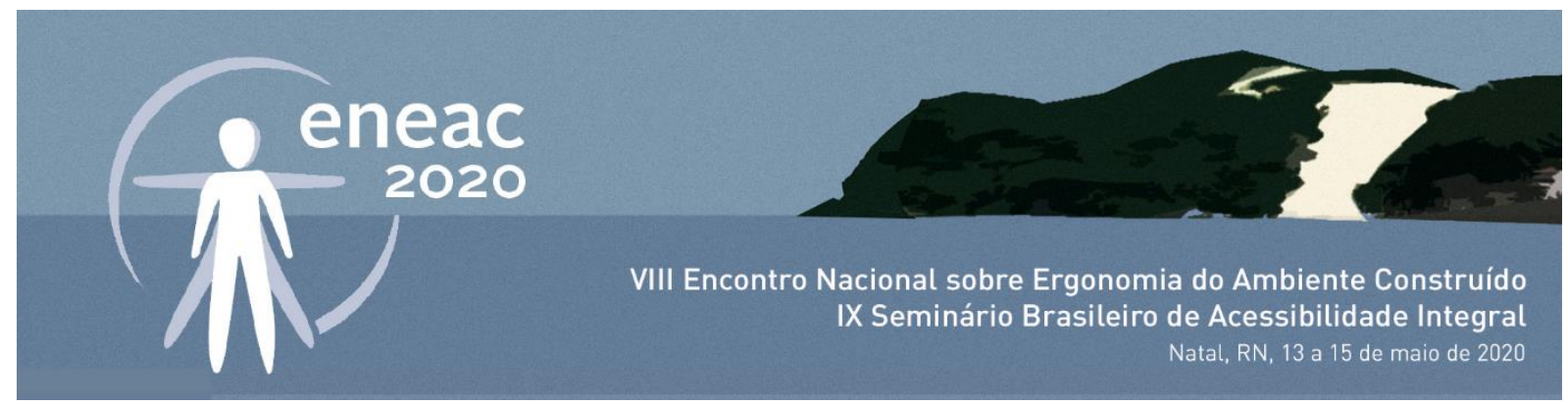

perceber a presença de ruídos externos provenientes do trânsito local, já que se trata de um edifício no centro de Blumenau (Figuras 7 e 8).

Figura 7: Sala 1

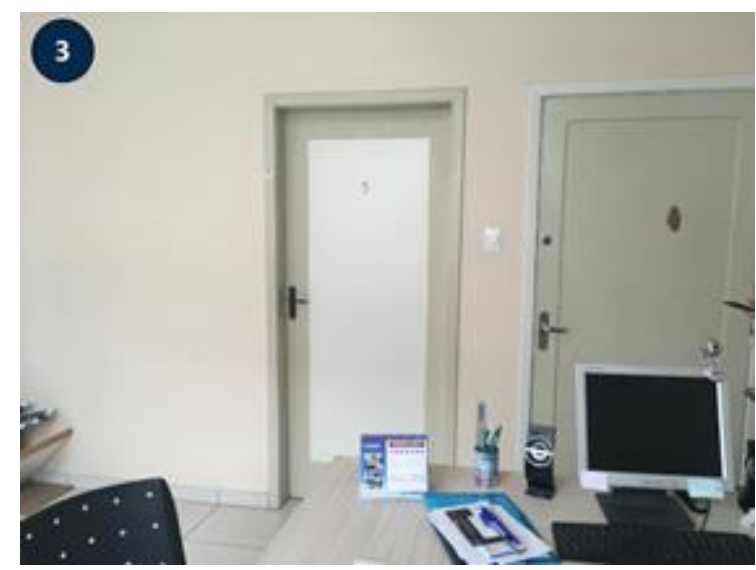

Fonte: Das autoras, 2019
Figura 8: Sala 1

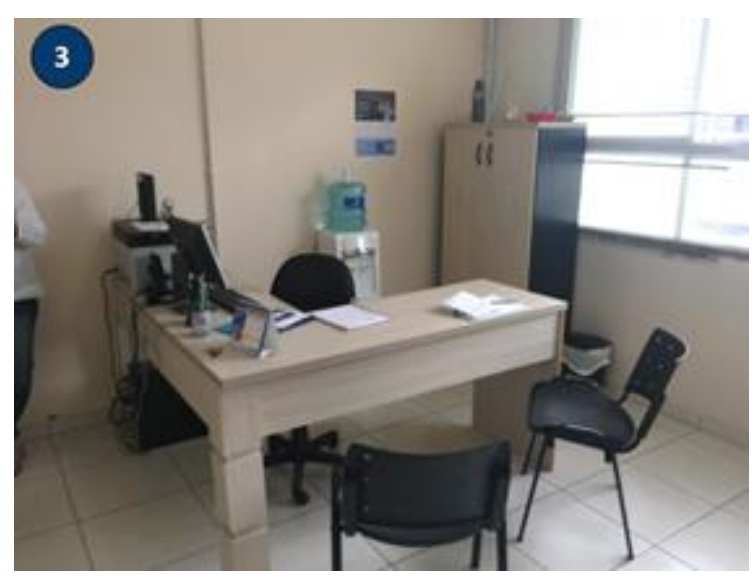

Fonte: Das autoras, 2019.

A Sala 02 tem $8,81 \mathrm{~m}^{2}$ e é destinada às atividades para as crianças com autismo, nela desenvolvem-se atividades de terapia ocupacional, fonoaudiologia e psicologia. A sala é equipada por um armário vertical que armazena brinquedos educativos de estimulação, um violão, um pequeno tapete emborrachado colorido, mesa e cadeira de plástico para crianças, além disso, brinquedos como grandes balões que são utilizados pelo terapeuta ocupacional.

Com relação à orientação solar, observa-se que a Sala 02 está localizada para o sul e possui uma pequena abertura. A orientação para o sul prejudica o conforto térmico dos usuários e a área da abertura dificulta a entrada de iluminação natural (Figuras 9 e 10). O conforto lumínico tem suma importância, é interessante permitir ampla incidência de luz natural, quanto a iluminação artificial é recomendado iluminação indireta para não causar desconfortos as crianças (EPIFANIO, 2018).

Figura 9: Sala 02

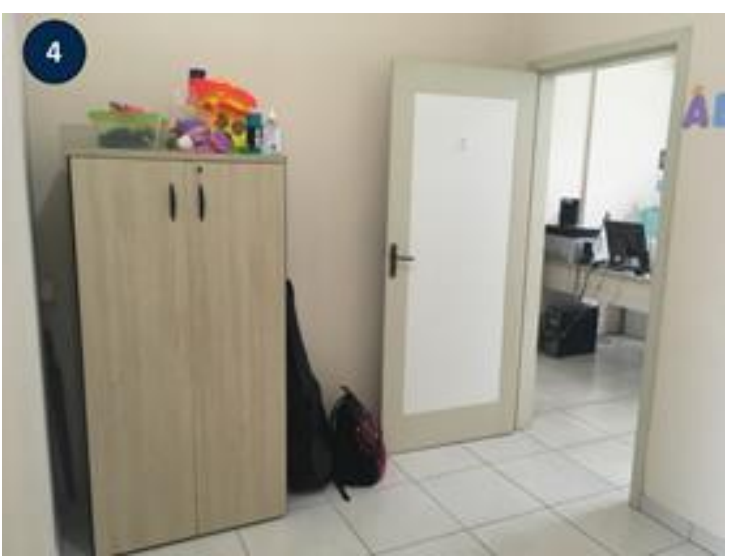

Fonte: Das autoras, 2019
Figura 10: Sala 02

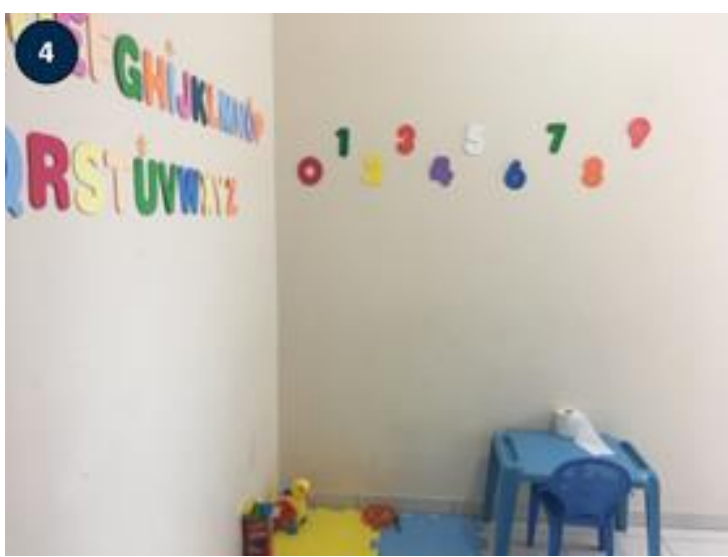

Fonte: Das autoras, 2019. 


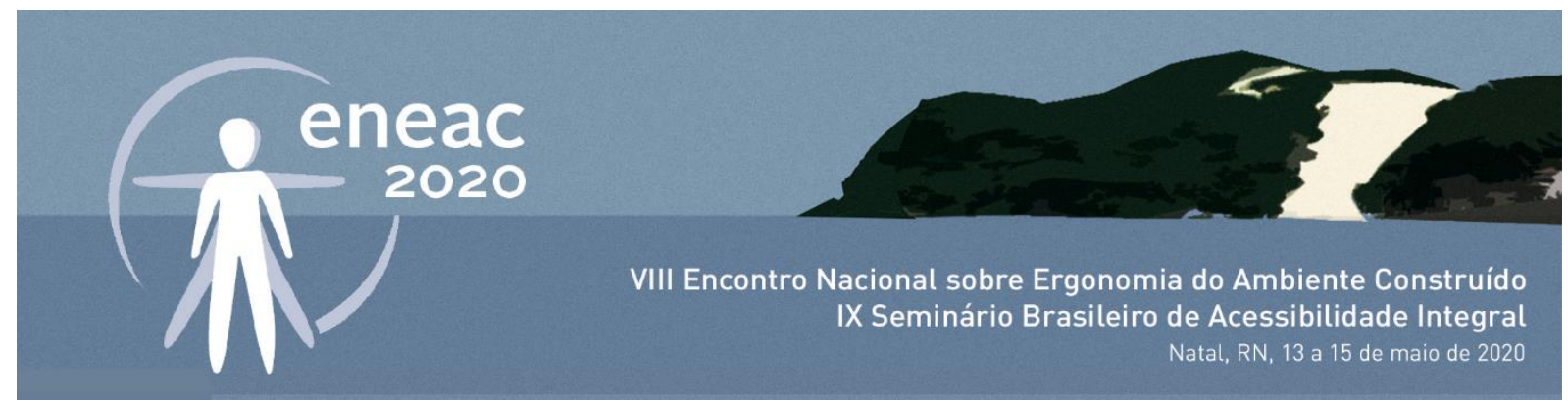

A Sala 03 possui $27,87 \mathrm{~m}^{2}$ e foi doada para a Instituição recentemente. A sala ainda não tem um uso definido, mas durante a visita pode-se notar que o espaço se caracteriza como uma espera para os pais ou responsáveis, enquanto o filho recebendo tratamento. Essa sala possui grande potencial em função boa insolação devido à grande abertura e a sua posição na fachada norte.

A luz natural não proporciona apenas iluminação ao espaço, mas também garante uma visão nítida e direta do espaço externo, podendo contribuir com as sensações e a integração do usuário entre o ambiente interno e externo (LAUREANO, 2017). Em relação ao mobiliário, observou-se que a sala possui uma mesa de escritório, cadeiras plásticas e um sofá, conforme mostra a Figura 11. Na Figura 12 é possível notar o corredor que faz acesso às duas salas e ao sanitário.

Figura 11: Sala 03

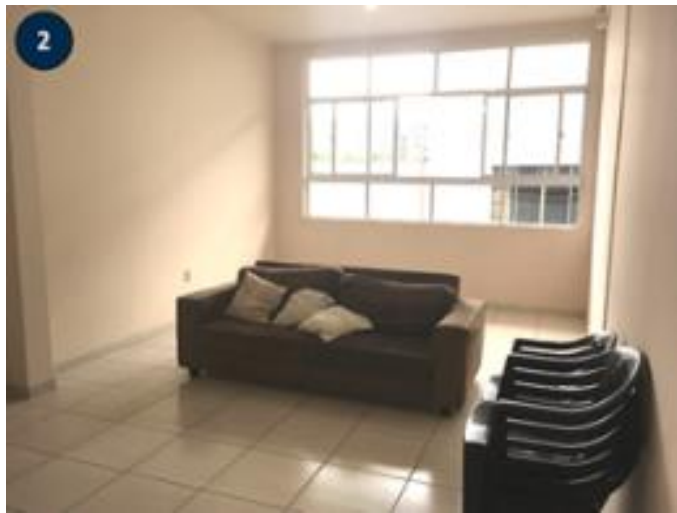

Fonte: Das autoras, 2019.
Figura 12: Circulação

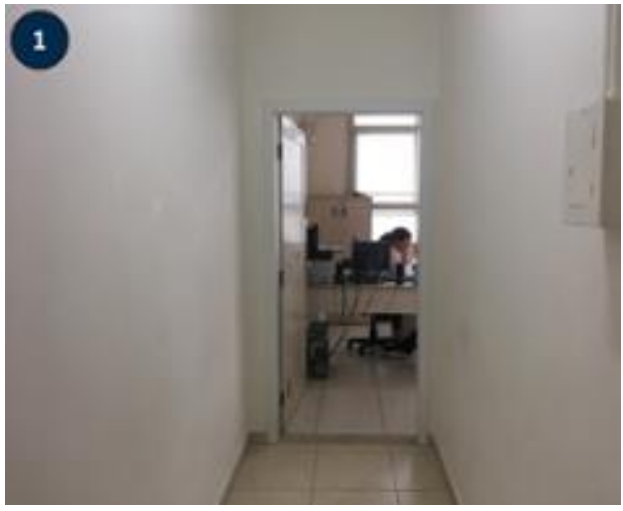

Fonte: Das autoras, 2019

Toda instituição possui apenas um único sanitário de $2,60 \mathrm{~m}^{2}$, que é utilizado pelos profissionais, pais e pelas crianças. Observa-se que as dimensões não são adequadas para o uso de cadeira de rodas, bem como o piso possui um desnível de $10 \mathrm{~cm}$ que impede a acessibilidade ao local, conforme mostra a Figura 13.

Figura 13: Banheiro

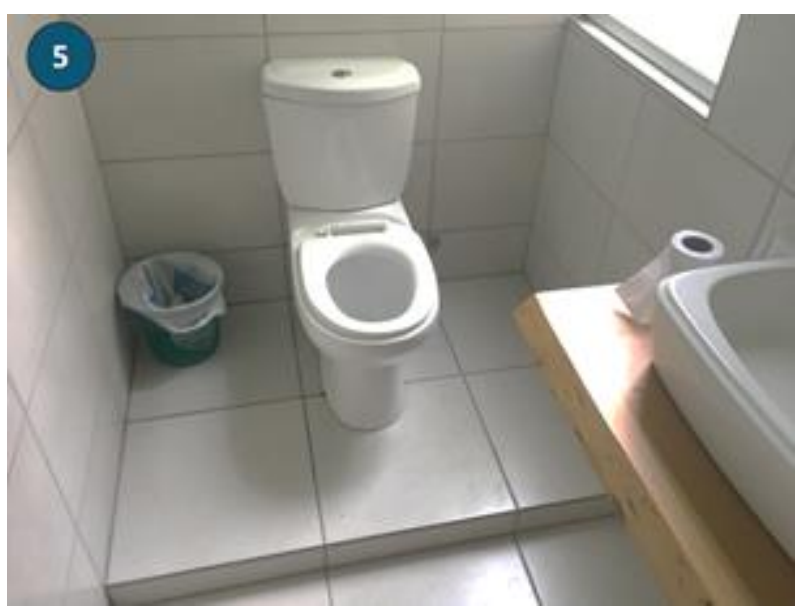




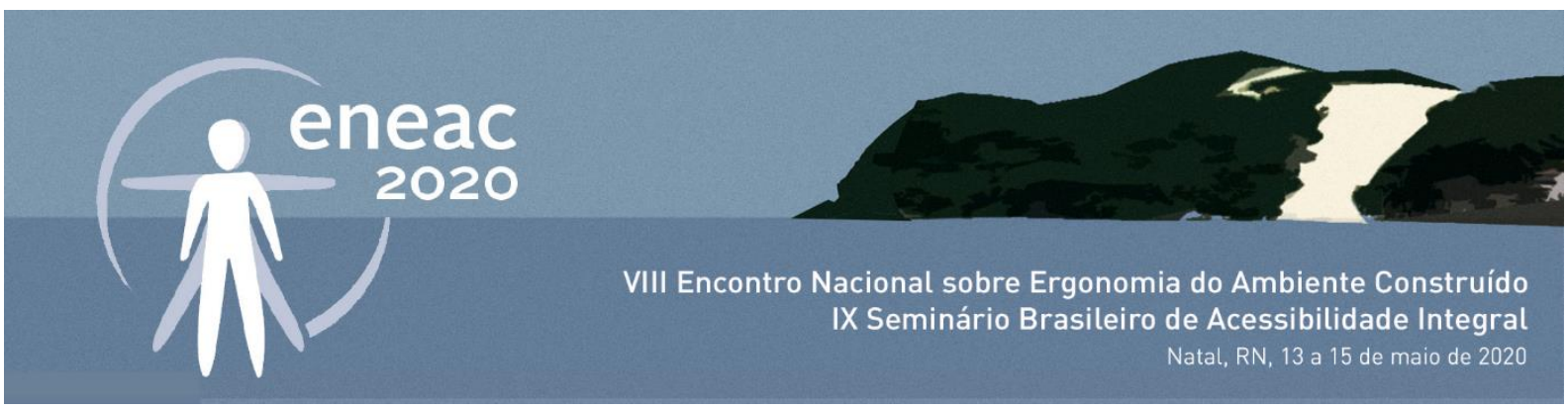

Fonte: Das autoras, 2019.

Sobre as formas arquitetônicas e o configuração do espaço, as mesmas podem ser consideradas simples e que podem oferecer flexibilidade de usos. As cores dos ambientes são neutras, variando em tons de beges e branco, cores mais marcantes são encontradas apenas nos brinquedos e elementos de estimulação ocupacional.

\begin{abstract}
As cores deverão ser neutras, em sua maioria, podendo ser aplicadas, em determinados elementos, cores mais marcantes, evitando o excesso dos estímulos oferecidos às crianças. [...] As cores fazem parte dos elementos que enriquecem o ambiente, exercendo grande influência nas terapias sensoriais. Através delas recebemos à energia de que necessitamos para manter o corpo e a mente sadios (LAUREANO, 2017).
\end{abstract}

Todos os ambientes possuem acabamento com alvenaria rebocada e pintada, da mesma forma que ambos possuem piso cerâmico em cor neutra. Segundo Laureano (2017), para ambientes de terapia sensorial "O acabamento dos pisos deverá ser de material emborrachado ou vinílico, não sendo recomendados pisos lisos e escorregadios, evitando pisos "frios". Em relação ao mobiliário, com exceção a mesa e cadeiras plásticas utilizadas pelas crianças para terapia, todos podem ser considerados adequados ergonomicamente para as funções que são destinadas.

"Os elementos que compõe o ambiente que devem ser considerados pela Ergonomia do Ambiente Construído, são aqueles referentes ao conforto ambiental (lumínico, térmico e acústico), à percepção ambiental (aspectos cognitivos), adequação de materiais (revestimentos e acabamentos), cores e texturas, acessibilidade, medidas antropométricas (layout, dimensionamento), e sustentabilidade. "Faz-se necessário uma abordagem sistêmica quando se trata de avaliar o ambiente sob a ótica da ergonomia" (VILLAROUCO, MONT'ALVÃO, 2011, p. 31 apud OLIVEIRA, MONT'ALVÃO, 2015).

Sobre a estrutura funcional, atualmente a instituição conta com 03 profissionais, sendo eles, um terapeuta ocupacional, uma fonoaudióloga e uma psicóloga, todos são contratados. Os atendimentos geralmente são individuais, com escalas de horários diversos. Atende-se crianças com faixa etária entre 0 e 14 anos de idade. Atualmente são atendidas 22 crianças, entre essas 19 são meninos e são 3 meninas de até 10 anos de idade. Quanto à fila de espera, há em média 52 crianças com autismo de até 10 anos de idade e 15 crianças com autismo com mais de 10 anos de idade, todas somente da cidade de Blumenau/SC. O Quadro 1 abaixo sintetiza as principais informações quanto à estrutura física e funcional da Instituição de Blumenau. 


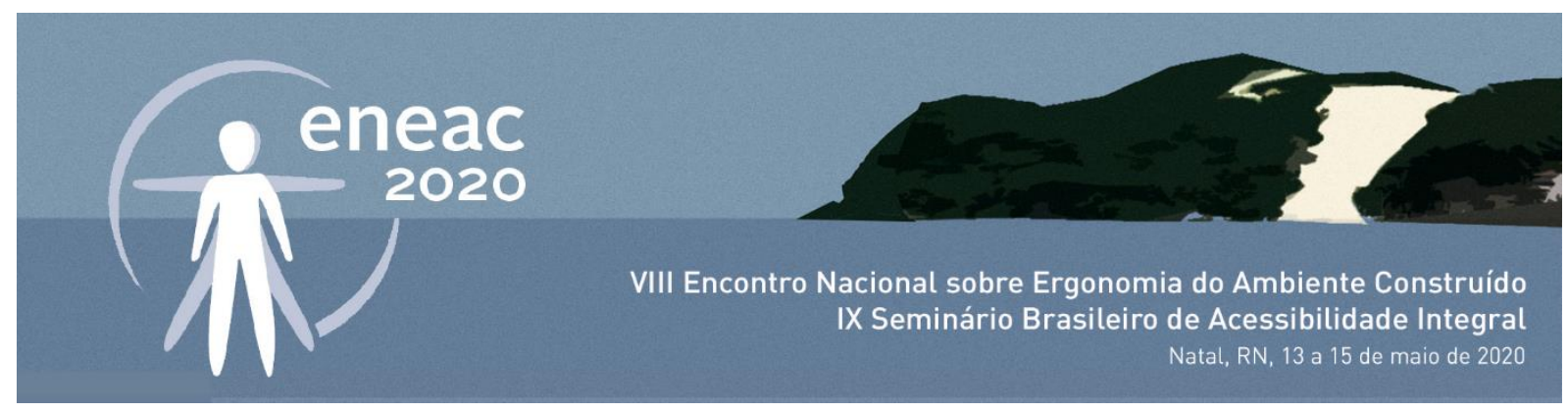

Quadro 1: Estrutura física e funcional

\begin{tabular}{|c|c|c|c|c|c|}
\hline \multicolumn{6}{|c|}{ ESTRUTURA FíSICA DA INSTITUIÇÃO } \\
\hline CÔMODO & ÁREA & MOBILIÁRIO & USO & CONFORTO AMBIENTAL & ERGONOMIA \\
\hline Sala 01 & $16,08 \mathrm{~m}^{2}$ & $\begin{array}{c}\text { Armário, mesas e } \\
\text { cadeiras de } \\
\text { escritório }\end{array}$ & $\begin{array}{l}\text { Recepção, ADM, } \\
\text { Reunião de Pais }\end{array}$ & $\begin{array}{c}\text { Boa insolação e } \\
\text { iluminação natural porém } \\
\text { há ruídos externos }\end{array}$ & $\begin{array}{l}\text { Não possui área } \\
\text { adequada para } \\
\text { reunião de pais }\end{array}$ \\
\hline Sala 02 & $8,81 \mathrm{~m}^{2}$ & $\begin{array}{c}\text { Armário, tapete } \\
\text { emborrachado, } \\
\text { cadeira e mesa } \\
\text { infantil, brinquedos }\end{array}$ & $\begin{array}{c}\text { Terapia } \\
\text { Ocupacional, } \\
\text { Fonoaudiologia, } \\
\text { Psicologia }\end{array}$ & $\begin{array}{c}\text { Pouca isolação e } \\
\text { iluminação natural, } \\
\text { menos ruídos externos }\end{array}$ & $\begin{array}{c}\text { Área insuficiente para } \\
\text { as atividades que são } \\
\text { realizadas }\end{array}$ \\
\hline Sala 03 & $27,87 \mathrm{~m}^{2}$ & $\begin{array}{l}\text { Mesa e cadeiras, } \\
\text { sofá dois lugares }\end{array}$ & $\begin{array}{l}\text { Espera de pais e } \\
\text { reuniões }\end{array}$ & $\begin{array}{l}\text { Boa insolação e } \\
\text { iluminação natural }\end{array}$ & $\begin{array}{l}\text { Área com grande } \\
\text { potencial para } \\
\text { atender diversas } \\
\text { atividades }\end{array}$ \\
\hline Circ & $4,33 m^{2}$ & Inexistente & Acesso salas e BW & $\begin{array}{l}\text { Pouca insolação e } \\
\text { iluminação natural }\end{array}$ & $\begin{array}{c}\text { Dimensões em } \\
\text { desacordo com a NBR } \\
9050\end{array}$ \\
\hline BW & $2,60 \mathrm{~m}^{2}$ & Pia, bacia sanitária & $\begin{array}{l}\text { Utilizado pelos } \\
\text { profissionais, pais } \\
\text { e crianças }\end{array}$ & $\begin{array}{l}\text { Pouca insolação e } \\
\text { iluminação natural }\end{array}$ & $\begin{array}{c}\text { Dimensões em } \\
\text { desacordo com a NBR } \\
9050\end{array}$ \\
\hline \multicolumn{6}{|c|}{ ÁREA TOTAL: 59,69m² } \\
\hline \multicolumn{6}{|c|}{ ESTRUTURA FUNCIONAL DA INSTITUIÇÃO } \\
\hline \multicolumn{6}{|c|}{$\begin{array}{l}\text { Três profissionais: Um terapeuta ocupacional, uma psicóloga e uma fonoaudióloga. } \\
\text { Atualmente atende } 22 \text { crianças de até } 10 \text { anos de idade. }\end{array}$} \\
\hline
\end{tabular}

Fonte: Das autoras, 2019.

\section{CONCLUSÕES}

Este estudo teve por objetivo analisar a estrutura física e funcional da instituição destinada ao apoio da criança autista na cidade de Blumenau. Os resultados obtidos contribuíram para evidenciar que a infraestrutura do local é insuficiente para atender a demanda existente, bem como proporcionar um ambiente de trabalho confortável para os pacientes e profissionais.

Em relação ao conforto térmico e acústico, as Salas 01 e 03 possuem boa ventilação e iluminação natural, porém possuem ruídos externos do trânsito local que podem influenciar no tratamento das crianças com hipersensibilidade. De outro modo, a Sala 01 é mais adequada em termos acústicos porém, possui pouca insolação por estar locada na fachada sul. As formas arquitetônicas e as cores podem ser consideradas adequadas, visto que são neutras e as cores marcantes encontram-se em objetos móveis.

Sobre a acessibilidade, observou-se o que acesso ao edifício e ao espaço da instituição é adequado, bem como, o entorno imediato urbano pode ser considerado agradável e seguro. No entanto, 


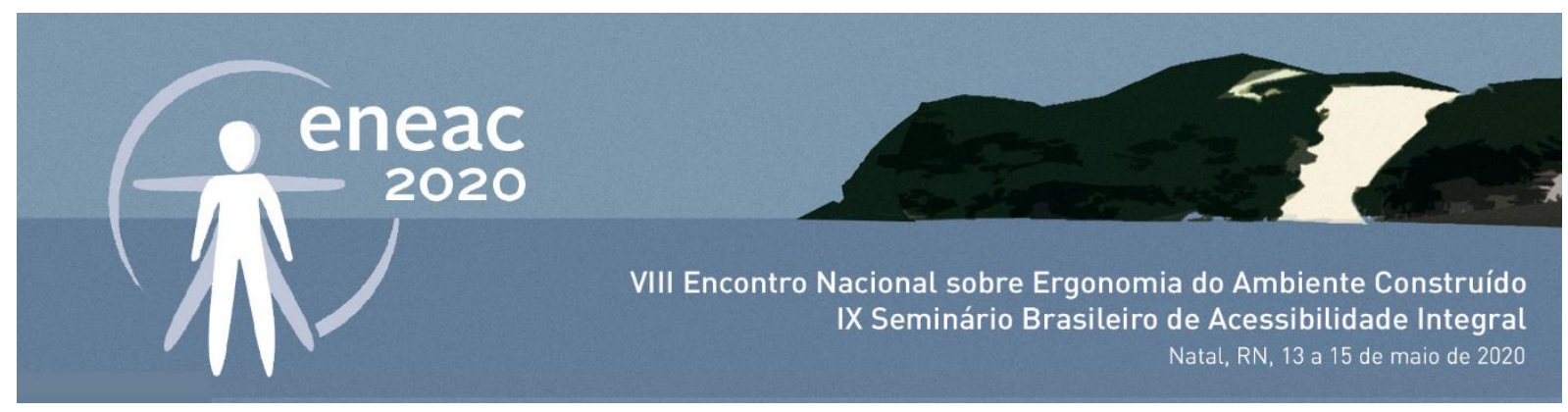

quando se trata da acessibilidade do ambiente interno, observou-se o quantitativo de sanitários é insuficiente, bem como não respeita a norma NBR 9050, pois possui um desnível para elevar a bacia sanitária e suas dimensões são estreitas. No que tange o mobiliário, observou-se que estes são insuficientes, possuem pouca durabilidade, pois são feitos de materiais plásticos, o que os torna mais frágeis e menos duráveis (mesa e cadeira infantil).

Com relação a estrutura funcional, constatou-se que a instituição possui poucos profissionais em função do orçamento limitado proveniente apenas de doações e outras atividades que arrecadam fundos, como venda de camisetas, pedágios solidários, entre outras. Isso resulta em um tempo de sessão terapêutica abaixo do necessário e filas de espera devido à impossibilidade de atender toda a demanda. Este orçamento limitado também influencia na aquisição de materiais adequados e brinquedos para as atividades de estímulo de desenvolvimento das crianças, uma vez que observouse que brinquedos são, em sua grande maioria, provenientes de doações.

A partir das pesquisas bibliográficas é possível concluir que espaços ao ar livre que permitem distintas atividades relacionadas a integração sensorial são de suma importância para as crianças com autismo, dessa forma, um espaço ideal para realizar tratamento deveria possuir ampla área livre ou que houvesse fácil acesso a um parque público por exemplo. Porém, a realidade da maioria das instituições sem fins lucrativos é outra em função do baixo orçamento, dessa forma, sugere-se que os espaços da instituição recebam adequações para fim de melhorar o tratamento e a qualidade de vida das crianças, pais/responsáveis e profissionais que ali frequentam.

Por fim, observa-se a necessidade de qualificar o espaço destinado às crianças com TEA em Blumenau, por meio de elementos construtivos, estratégias de conforto ambiental, materiais e equipamentos/brinquedos adequados que atendam às necessidades das crianças com Transtorno do Espectro Autista a fim de contribuir com o desenvolvimento aliando com uma arquitetura inclusiva.

\section{REFERÊNCIAS}

AGUIAR, Traduzido e Adaptado Por Vinicius. DEFINIÇÃO: Transtornos do espectro do autismo: Nota OMS de Abril de 2017. 2017. Disponível em: <https://www.ama.org.br/site/autismo/definicao/>. Acesso em: 01 abr. 2019.

BRASIL. Lei no 7.853, de 24 de outubro de 1989. Dispõe sobre o apoio às pessoas portadoras de deficiência, sua integração social, sobre a Coordenadoria Nacional para Integração da Pessoa Portadora de Deficiência - Corde, institui a tutela jurisdicional de interesses coletivos ou difusos dessas pessoas, disciplina a atuação do Ministério Público, define crimes, e dá outras providências. Disponível em: <http://www.planalto.gov.br/ccivil_03/leis/L7853.htm>. Acesso em: 09 abr. 2019.

Design de Interiores. Estudos em Design, v. 23, n. 3, p. 150165, 2015.

LAUREANO, Claudia de Jesus Braz. Recomendações projetuais para ambientes com atendimento de terapia sensorial direcionados a crianças com autismo. 190 f. Dissertação (Mestrado em Arquitetura e Urbanismo) - Universidade Federal de Santa Catarina, Florianópolis, 2017.

LEPLAT, J.; MONTMOLLIN, M. As relações de vizinhança da ergonomia com outras disciplinas. In: FALZON, P. (Ed.). Ergonomia. São Paulo: Edgard Blucher, 2007. p. 33-44. MONTMOLLIN, M. Vocabulaire de I'Ergonomie. Tolouse, France: Octarès Editions, 2007. 


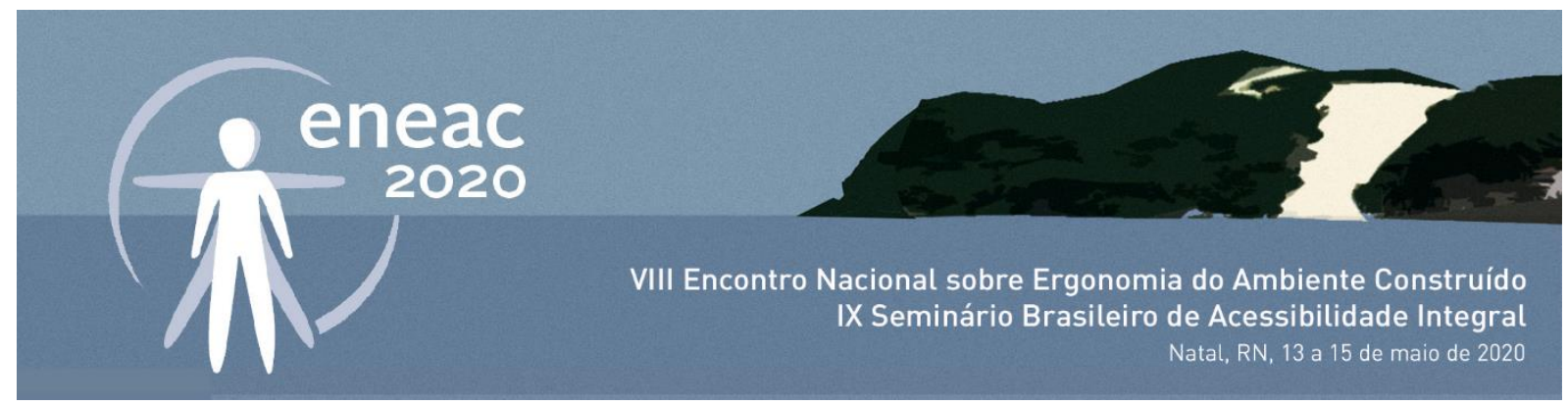

LUCIO, Cristina do Carmo. Análise da acessibilidade e usabilidade de equipamentos médico-hospitalares para pacientes obesos da cidade de Bauru (SP). 110f. Dissertação (Mestrado) - Universidade Estadual Paulista. Faculdade de Arquitetura, Artes e Comunicação, Bauru, 2007.

MENDES, Jaqueline Izabela; COSTA, Juliane Rissardi. Integração Sensorial em crianças com Transtorno do Espectro Autista. Cadernos da Escola de Saúde. v. 17.p. 1-, 2017.

MULLER, Marcelle Suzete; ALMEIDA, Eloisa Santa de; TEIXEIRA, Fábio Gonçalves. Design inclusivo: Playground para Todas as Crianças. In: Human Factors in Design, v.3, n.5, p 02 - 27, 2014.

O QUE é transtorno do espectro do autismo? 2018. Disponível em: <https://www.cdc.gov/ncbddd/autism/facts.html>. Acesso em: 01 abr. 2019.

OLIVEIRA, Gilberto Rangel; MONT"ALVÃO, Claudia Renata. Metodologias utilizadas nos estudos de Ergonomia do Ambiente Construído e uma proposta de modelagem para projetos de ORNSTEIN, SHEILA WALBE. Postoccupancy evaluation performed in elementary and high schools of greater São Paulo, Brazil: The occupants and the quality of the school environment. In: Environment and Behavior, 1997.

ROMERO, M.A.; ORNSTEIN, S.W. Avaliação Pós-Ocupação. Métodos e Técnicas Aplicados à Habitação Social. São Paulo: Faculdade de Arquitetura e Urbanismo da Universidade de São Paulo. Associação Nacional de Tecnologia do Ambiente Construído; Financiadora de Estudos e Projetos, 2003 (Coletânea Habitare/FINEP,1).

SCHMIDT, Carlos. Autismo, educação e transdisciplinaridade. Brasil: Papirus, 2013. 240 p.

SILVA, Micheline; MULICK, James A. Diagnosticando o transtorno autista: aspectos fundamentais e considerações práticas. Psicologia: Ciência e Profissão. v. 29, p. 116-13, 2009.

SOARES, Jéssica Martins de A. Centro de Desenvolvimento do Autismo. 72 f. TCC (Graduação em Arquitetura e Urbanismo) - Pontifícia Universidade Católica de Goiás, Goiânia, 2017.

VERGARA, Lizandra Garcia Lupi; TRONCOSO, Marcia Urbano; RODRIGUES, Gabriela Vargas; "Acessibilidade entre mundos: uma arquitetura mais inclusiva aos autistas", p. 536-546. In: São Paulo: Blucher, 2018.

WHITMAN, Thomas L.. O Desenvolvimento do Autismo. São Paulo: M.books do Brasil Editora Ltda, 2015.

YIN, R. K. Estudo de caso: planejamento e métodos. Traduzido por Daniel Grassi, 2a ed. Bookman. Porto Alegre, 2001. 